\title{
Effects of habitat composition on recruitment of cerithid gastropods in sediments at One Tree Reef, Great Barrier Reef
}

\author{
G. A. Skilleter, A. J. Underwood \\ Institute of Marine Ecology, Zoology Building, AO8, University of Sydney, New South Wales 2006, Australia
}

\begin{abstract}
Cerithiid gastropods (Rhinoclavis spp.) are common in sediments at One Tree Reef (southern Great Barrier Reef, Australia). They are more abundant in and recruit more abundantly to coarse sandy sediments than in finer sands in the lagoon. Recruitment in different habitats could differ because, in some places, fewer larvae arrive or because fewer larvae are able to settle. In this study, experimental transplants of sediments were used to determine the influence of small-scale variations in substratum on the recruitment of the snails. We predicted that if different substrata influence recruitment and were available in one place (where similar numbers of larvae arrive) recruitment should vary among substrata. Sandy substrata of different composition from 4 locations were transplanted in plastic tubs into 2 locations in and 2 locations away from the lagoon, with replicated sites in each location. Recruitment of 3 species of Rhinoclavis and of Cerithium zonatum was significantly affected by the available sediments. Generally, where there were differences, numbers of recruits were greater in coarse sediments, but results varied from location to location and species to species. The experiments were capable of demonstrating variations in recruitment in response to the type of sediment. Recruitment was, however, not greater in coarser sediments placed in the lagoon (except for Rhinoclavis aspera). Thus, the smaller recruitment in the lagoon cannot be explained by lack of suitable substrata. Further work is needed to determine the patterns of availability of the larvae in different habitats and the processes that influence choice of substratum.
\end{abstract}

\section{INTRODUCTION}

Two aspects of 'habitat structure' which may be important in determining the abundance and number of species in assemblages are micro-habitat diversity and habitat composition (e.g. McGuinness \& Underwood 1986). In soft-sediments, micro-habitat diversity has frequently been studied with respect to the presence of small biogenic structures, such as worm tubes, which can influence patterns of settlement and/or recruitment (Eckman 1979, 1983, Eckman et al. 1981, Woodin 1981, Gallagher et al. 1983), or provide refuges from the effects of predation (Woodin 1978).

Habitat composition refers to the material making up the substratum (clays, muds, sands, etc.) and is usually described in relation to the mean size and the range of sizes (sorting) of the particles present (Gray 1974). Studies done primarily in the laboratory have shown that interactions between habitat composition and physico-chemical variables, including the porosity of the sediments, their oxygen content, associated microbes and their overall stability, can influence the patterns of distribution and abundance of infauna (reviewed by Hartnoll 1983)

Only a few studies have directly manipulated bottom sediments to address the question of the effects of habitat composition on settlement or recruitment of infaunal molluscs in the field (Butman 1987). Zajac \& Whitlatch (1982) compared 'recolonisation' into mud and sand at 3 different sites, but did not specifically distinguish between recruitment (sensu Keough \& Downes 1982) and recolonisation by surrounding resident fauna. Even so, they reported very few significant differences in 'recolonisation' between the 2 sediments. Williams (1980), however, found significant differences in settlement of clams into sediments col- 
lected from 2 heights on an intertidal beach. He transplanted the sediments from high to low areas to determine whether the observations were due to differences in the sediments or to confounded effects of the fact that the 2 areas were simply different places.

Cerithiid gastropods of the genus Rhinoclavis are among the most abundant molluscs in sediments at One Tree Reef, on the southern Great Barrier Reef, Australia (Skilleter 1991). Despite being microphagous deposit-feeders (Houbrick 1978), these snails reach their greatest abundances in coarse, sandy sediments on a shallow, subtidal sandflat (Skilleter 1991, 1992), a habitat usually considered to be atypical for deposit-feeding infauna. The smaller densities of Rhinoclavis spp. in the lagoonal sediments compared with the southern sandflat were explained, in part, by the greater recruitment to the former habitat (Skilleter 1992). Previous work in other systems (Crowe et al. 1987, Hunt et al. 1987, Commito \& Boncavage 1989, Hines et al. 1989) had demonstrated the importance of resident infauna on the recruitment of other organisms in sediments, but, at One Tree Reef, experimental removal of established adult molluscs from the sediments in the lagoon did not lead to consistently greater recruitment in this habitat and could not explain the observed patterns of abundance. Thus, other mechanisms were apparently important (Skilleter 1992).

The smaller numbers of recruits of Rhinoclavis spp. in the sediments of the lagoon compared with the sandflat and the variation in recruitment from location to location on the sandflat could be explained by several general models (Underwood 1979, Connell 1985): (1) the substratum in the lagoon (or at different locations on the sandflat) may represent a habitat which is 'unsuitable' for the settlement and/or survivorship of the larvae of Rhinoclavis spp.; thus fewer larvae choose to settle in these sediments or fewer survive until the time of first census; (2) fewer planktonic propagules actually arrive in the water column over the sediments in the lagoon; (3) conditions in the water column over the lagoonal sediments prevent larvae from settling there

Differences in the rates of settlement among different substrata have been established for a number of phyletic groups although the mechanisms behind these differences are hotly debated (Butman 1987. especially Table VI). Here, we examined the model that the lesser recruitment of Rhinoclavis spp. in the lagoon and the variation in recruitment on the sandflat, were functions of the type of sediment in each habitat (Model 1). Specifically, we tested the hypothesis that transplanting sandy sediments from the sandflat into the lagoon would lead to an increase in recruitment of Rhinoclavis spp. in the lagoon. Reciprocal transplants of sediments from the lagoon onto the sandflat were also done so that we could still assess the effects of habitat composition on the recruitment of Rhinoclavis spp. even if few recruits reached the lagoon due to other factors (e.g. larval depletion).

\section{MATERIALS AND METHODS}

Study site. This study was done at One Tree Reef $\left(23^{\circ} 30^{\prime} \mathrm{S}, 152^{\circ} 06^{\prime} \mathrm{E}\right)$, on the eastern edge of the Capricorn Group of reefs on the southern Great Barrier Reef. Sites used for the experiment were located on the southern sandflat and in the adjacent channel (southern channel) that extended along the southern side of the main lagoon. Detailed descriptions of each of these habitats can be found in Jones et al. (1990) and Skilleter (1991).

Effects of different substrata on recruitment. We used small plastic tubs (internal dimensions $394 \times 284$ $\times 108 \mathrm{~mm}$ ) to enclose 4 different types of sediment collected from different habitats within One Tree Lagoon in order to determine the effects of different substrata on the recruitment of Rhinoclavis spp. (see Skilleter 1992 for a description of the tubs). The 4 sediments were classified according to the mean size of particles: (1) very coarse sediment collected from the sandflat near the edge of the intertidal carbonate platform; mean grain size $(\phi)=0.95 ;(2)$ coarse sediment collected from the centre of the sandflat; mean grain size $(\phi)=1.20 ;$ (3) medium sediment collected from the southern channel lagoon; mean grain size $(\phi)=2.10$; (4) fine sediment collected from the northern channel of the lagoon; mean grain size $(\phi)=2.70$.

Tubs were set up at 4 locations in December 1988, 2 on the sandflat and 2 in the southern channel, the section of the main lagoon adjacent to the sandflat. The 2 locations on the sandflat were used because this habitat had received relatively large numbers of recruits in previous years (Skilleter 1991, 1992). If the lesser recruitment into the lagoon was a function of larval depletion by settlement on the sandflat and few larvae normally reach the lagoon then we would still be able to assess the affects of habitat composition on recruitment using just the data from the 2 locations in this habitat. The locations in the southern channel were chosen to determine whether lesser recruitment in areas away from the sandflat was related to the lack of a suitable substratum (whether for settlement or subsequent early survival) in these areas. The coarse and very coarse sediments were used to determine if the variability in recruitment among locations on the sandflat was related to small differences in the sediment within that habitat. Similarly, the medium and fine sediment assessed this question for the lagoonal habitats. 
Three replicates of each sediment treatment were set up at each of 2 sites approximately $10 \mathrm{~m}$ apart within the 4 locations. Treatments were assigned at random to the 12 tubs at each site. Tubs were positioned approximately $2 \mathrm{~m}$ apart to allow easy movement between them for access to remove fouling organisms (mainly algae). Sediment for each treatment was collected from the appropriate habitat by sieving the sand through $1 \mathrm{~mm}$ sieves directly into large plastic bags with the entrance partially sealed to avoid loss of the fine silt fraction. The coarse sediment retained in the $1 \mathrm{~mm}$ sieve was hand-sorted to remove any large macrofauna and then added to the bags. This procedure did not remove groups such as polychaetes or crustaceans which were abundant in these sediments (personal observation). The sediment in each bag was mixed by hand for about 5 min to re-distribute the coarse material before the bag was sealed for transport to the locations used for the experiment. Bags of sediment were out of water for a maximum of 30 min during transportation, but a small amount of water was sealed in each bag to keep the sediment wet. The sediment was placed into the experimental tubs on the day of collection. At each site, sediments were excavated to a depth of approximately 60 to $70 \mathrm{~mm}$ and the tubs placed so that the sides protruded 38 to $48 \mathrm{~mm}$ above the surface of the substratum forming a fence enclosing the sediment contained within the tubs Usually several $\mathrm{cm}$ of the hard coral base under the sediment were removed with a cold-chisel and lump hammer allowing the tubs to be securely wedged into the hole. The tops of the tubs were left open.

A core of sediment was collected from each tub to determine the mean size of particles in each treatment at the start of the experiment (see below). The experiment started in the third week of December 1987. At the start of January 1988, samples were taken from the sandflat and in the channel to check for the presence of recruits (see Skilleter 1992).

Three weeks after recruits were first detected on the sandflat, all tubs were collected and transferred, intact, to the laboratory and kept in a flow-through seawater system. A core of sediment was collected from each tub to determine whether any changes in the grain-size of the sediment had occurred during the experiment (e.g. from scouring). Cores of sediment were collected using a $5 \mathrm{~cm}$ diameter perspex corer pushed $7 \mathrm{~cm}$ into the sand. Cores were first checked for the presence of recruits then each core was transferred to a labelled bag using a small amount of water to wash any sediment adhering to the insides of the corer and fixed in $5 \%$ neutral formalin. Samples were dried to constant weight at $60^{\circ} \mathrm{C}$. The silt fraction (less than $63 \mu \mathrm{m}$ ) was wet sieved from the sample and the remaining sediment re-dried to constant weight. The $<63 \mu \mathrm{m}$ fraction was calculated as the loss in weight after wet sieving. The remaining sediment was then sieved into the following fractions: $>1,0.5-1,0.25-0.5,0.125-0.25$, 0.0625-0.125 mm, using an automatic sieve shaker. Each fraction was weighed and recorded as a percentage weight of the total sample. The mean particle size and standard deviation (sorting coefficient), for each sample was calculated using the method of moments (Folk 1974) which calculates values in the phi $(\phi)$ scale.

The remaining sediment from the tubs was sieved through $750 \mu \mathrm{m}$ mesh sieves and the samples were fixed in $10 \%$ formalin/seawater with Biebricht Scarlet stain for $24 \mathrm{~h}$. Samples were washed and stored in $70 \%$ ethanol and then sorted in the laboratory. Juvenile molluscs were stained bright pink and were easily sorted from the white carbonate sands.

\section{RESULTS}

There was evidence of small amounts of scouring around the edges of the tubs at all locations and the mean grain size of the sediments within the tubs changed compared with the initial grain size used IANOVA of grain size in the treatments (Sediment) from the beginning to the end (Time) of the experiment, Sediment $\times$ Time interaction, $p<0.01$, StudentNewman-Keuls (SNK) tests in Fig. 1]. The sediment in each treatment was coarser at the end of the experiment than at the start, but the differences among the 4 treatments were essentially the same for the duration of the experiment (Fig. 1).

Four species of cerithiid gastropods recruited in relatively large numbers to the experimental tubs at the 4 locations: Rhinoclavis aspera (Linnaeus, 1758), $R$. fasciata (Bruguière, 1792), $R$. vertagus (Linnaeus,

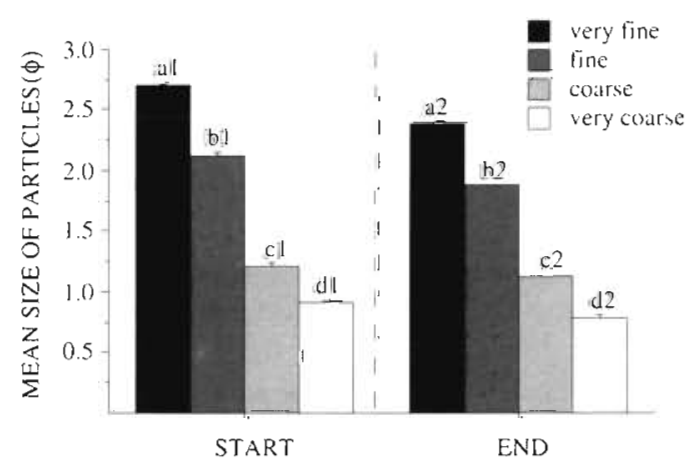

Fig. 1. Mean $(+\mathrm{SE})$ size of particles $(\phi)$ in the 4 sediments at the start and end of the experiment examining effects of sediment composition on recruitment. Error bars which are not visible are too small to be shown. Sediments with different lettering have significantly different mean size of particles $(p<0.05 ;$ SNK tests after 2-way ANOVA) 
Table 1. Rhinoclavis aspera, $R$. fasciata, $R$. vertagus and Cerithium zonatum. Results of 3-factor ANOVA comparing densities in 4 different types of sediment in experimental enclosures at 4 locations and 2 sites within each location. Location (L) and Sediment (S) were fixed factors; Sites were nested within Locations and were random. Data were transformed to loge $(x+1)$ to meet assumptions of homoscedasticity after Cochran's tests $(\alpha=0.05)$. For $R$ aspera, $R$. fasciata and $R$. vertagus, the interaction between sediments and sites [S $\times$ Sites (L)] was non-significant at $p=0.25$ and the mean square and degrees of freedom for this term were pooled with those of the residual (Winer 1971. Underwood 1981). " $p<0.05 ; \cdots p<0.01 ; \cdots p<0.001$ i ns: not significant $(p>0.05)$

\begin{tabular}{|c|c|c|c|c|c|c|c|c|c|c|c|c|c|}
\hline \multirow[t]{2}{*}{ Source } & \multirow[t]{2}{*}{$\mathrm{df}$} & \multicolumn{3}{|c|}{ R. aspera } & \multicolumn{3}{|c|}{ R. fasciata } & \multicolumn{3}{|c|}{ R. vertagus } & \multicolumn{3}{|c|}{ C. zonatum } \\
\hline & & MS & $\stackrel{k}{F}$ & $\mathrm{p}$ & MS & $F$ & $\mathrm{p}$ & MS & $F$ & $p$ & $\mathrm{MS}$ & $F$ & $\mathrm{p}$ \\
\hline Location & 3 & 7.75 & 48.73 & $\cdots$ & 2.11 & 67.19 & $\cdots$ & 4.39 & 39.00 & $\cdots$ & 32.88 & 256.29 & $\cdots$ \\
\hline Sites (L) & 4 & 0.16 & 0.47 & ns & 0.03 & 0.27 & ns & 0.11 & 0.99 & ns & 0.13 & 0.52 & ns \\
\hline Sediment & 3 & 18.39 & 52.26 & $\cdots$ & 0.50 & 4.93 & $\cdot$ & 2.55 & 16.70 & $\cdots$ & 8.73 & 9.98 & $\cdots$ \\
\hline $\mathrm{L} \times \mathrm{S}$ & 9 & 2.40 & $7.05^{d}$ & $\cdots$ & 0.79 & $6.80^{d}$ & $\cdots$ & 1.35 & $11.29^{\mathrm{a}}$ & $\cdots$ & 5.10 & 20.40 & $\cdots$ \\
\hline $\mathrm{S} \times$ Sites (L) & 12 & 0.35 & 1.04 & ns & 0.10 & 0.86 & ns & 0.15 & 1.35 & ns & 0.88 & 3.52 & $\cdots$ \\
\hline Residual & 64 & 0.34 & & & 0.12 & & & 0.11 & & & 0.25 & & \\
\hline Pooled ${ }^{b}$ & 76 & 0.34 & & & 0.12 & & & 0.12 & & & & & \\
\hline
\end{tabular}

1758) and Cerithium zonatum (Wood, 1828). Recruitment of these species was significantly affected by the type of substratum in the tubs, but the differences among the types of sediment varied among the 4 locations examined (ANOVA; $\mathrm{L} \times \mathrm{S}$ interaction; $\mathrm{p}<0.001$; Table 1). There was no significant variation in recruitment at the smaller spatial scale of sites for the 3 species of Rhinoclavis, although there was a significant interaction between Sediment type and Sites for C. zonatum (ANOVA; Table 1).

Significantly more recruits of Rhinoclavis aspera occurred in the coarse sediment collected from the centre of the sandflat than in the other types of sediment at 3 of the 4 locations used (SNK tests; Fig. 2). Recruitment was up to 28 times greater in this sediment than in either of the sediments from the lagoon. At these same 3 locations, there were significantly more $R$, aspera recruits found in the coarse sediment, than the very coarse sediment even though both came from the sandflat. There were no significant differences in recruitment between the fine and medium sediments collected from the lagoon, except at a single location in the lagoon where the medium grade sediment received more recruits than the fine grade (Fig. 2). Transplanting the coarse or very coarse sediments from the sandflat into the lagoon led to significantly increased recruitment of $R$. aspera at one of the locations in the southern channel but not the other (SNK tests; Fig. 2).

Recruitment of Rhinoclavis fasciata was sparse at all locations, with only the occasional specimen being found at some of the locations (Fig. 3). At one location on the sandflat, there were significantly more recruits in the coarse sediment, at the other there were significantly more recruits in the very coarse sediment (SNK
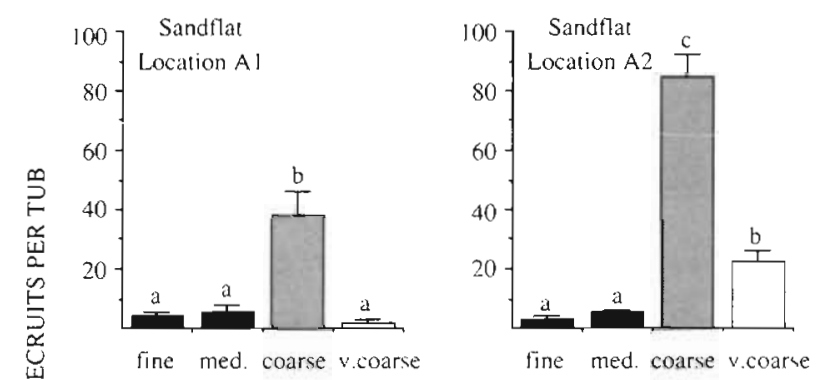

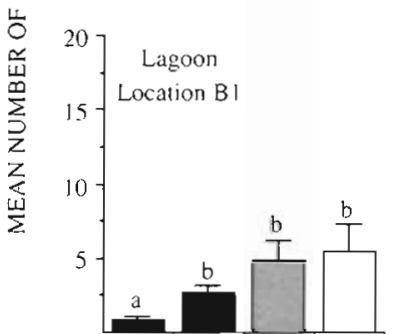

fine med. coarse v coarse

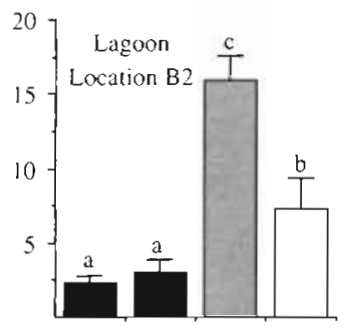

fine med. coarse v.coarse
TYPE OF SEDIMENT

Fig. 2. Rhinoclavis aspera. Mean ( $\mathrm{SE}$ ) number of recruits of in 4 different sediments at each of 4 locations ( $n=6$ tubs; 3 tubs from each of 2 sites). A1 and A2 are on the southern sandflat; B1 and B2 are in the southern channel. Treatments with different lettering have significantly different mean numbers of recruits ( $p<0.05$; SNK tests)

tests; Fig. 3). Both these sediments were from the sandflat. Interestingly, recruits of $R$. fasciata did not occur in the very coarse sediment at any of the other locations except for a single specimen in one tub in the south channel (Fig. 3). Transplanting sediment from the sandflat into the lagoon did not increase recruitment of R. fasciata into this habitat (SNK tests; Fig. 3). 


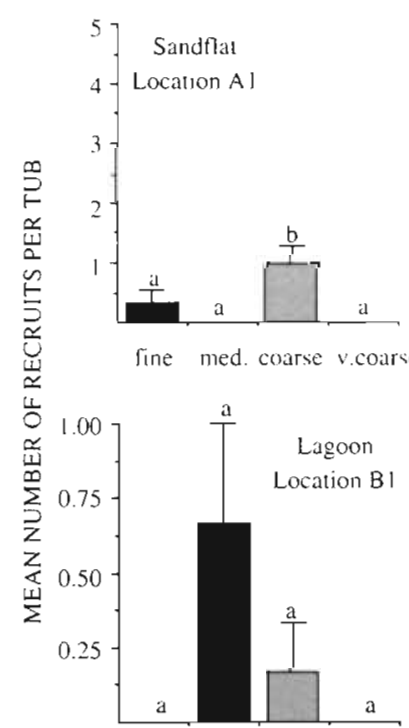

fine med. coarse v.coarse

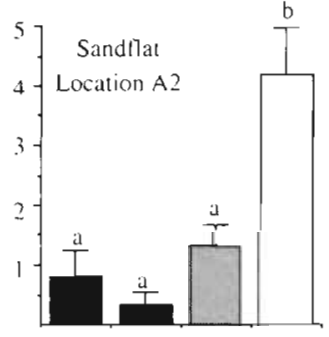

fine med. coarse v.coarie

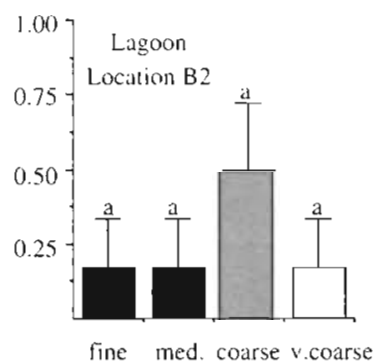

fine med coarse v.coarse

TYPE OF SEDIMENT

Fig. 3. Rhinoclavis fasciata. Mean (+ SE) number of recruits in 4 different sediments at each of 4 locations. Other details as in Fig. 2

For Rhinoclavis vertagus, recruitment was significantly greater in the coarse sediment compared with the other sediments at both locations on the sandflat (SNK tests; Fig. 4). At one of these locations, there were also significantly more recruits in the very coarse

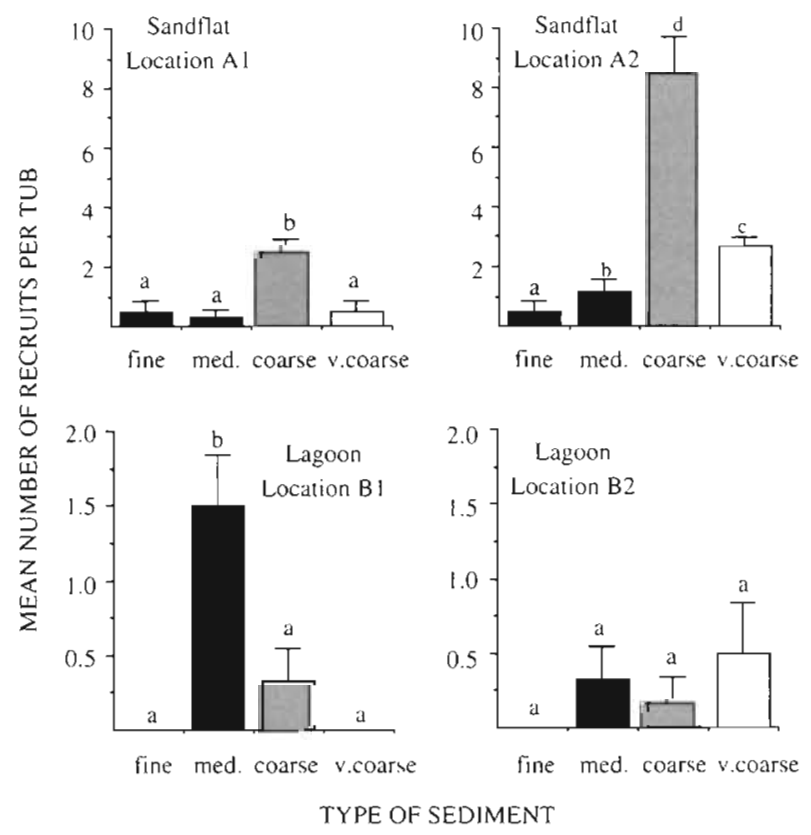

Fig. 4. Rhinoclavis vertagus. Mean ( $+\mathrm{SE})$ number of recruits in 4 different sediments at each of 4 locations. Other details as in Fig. 2

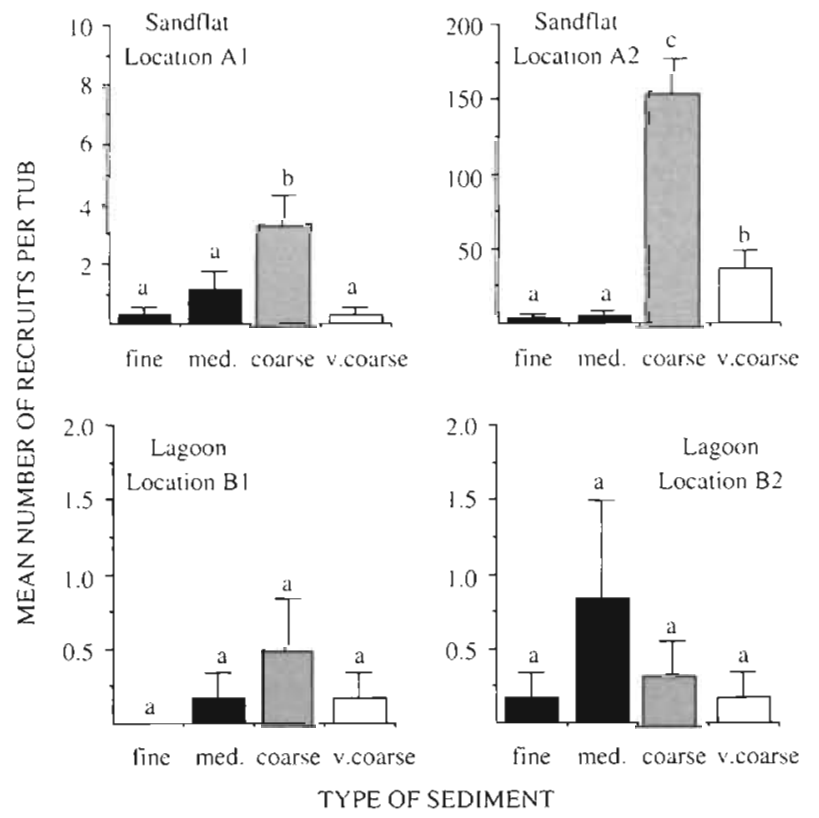

Fig. 5. Cerithium zonatum. Mean (+ SE) number of recruits in 4 different sediments at each of 4 locations. Other details as in Fig. 2

sediment than in either of the 2 substrata from the channels (Fig. 4). Recruitment of $R$. vertagus was not increased in the lagoon by the presence of sediment from the sandflat. In fact, at one of the locations in the lagoon there were significantly more recruits in the medium sediment than all others (SNK tests; Fig. 4), although numbers of recruits of $R$. vertagus were generally small in the lagoon. The medium sediment is the ambient sediment in the southern channel.

Recruitment of Cerithium zonatum was significantly greater in the coarse sediment than the other sediments at both the locations on the sandflat, but there were no significant differences among any of the sediments planted in the lagoon (SNK tests; Fig. 5). At one of the sandflat locations, recruitment of $C$. zonatum was also greater in the very coarse sediment than either of the lagoonal sediments (A2; Fig. 5); the same pattern as for Rhinoclavis vertagus, Location A2 received the greatest number of recruits of all species. Transplanting sediment from the sandflat into the lagoon did not increase recruitment of $C$. zonatum into this habitat (Fig. 5).

\section{DISCUSSION}

We examined the hypothesis that recruitment of cerithiid gastropods to habitats in the lagoon at One Tree Reef was restricted by the lack of coarse sandy sediments in these habitats. Each of the 4 species 
examined here was most abundant in the sandy sediments on the southern sandflat and recruitment to this habitat was greater than to the fine sediments in the channels (Skilleter 1992). If the fine substratum in the lagoon were unsuitable for settlement and/or survivorship of cerithiid larvae, then transplanting the coarse sediments from the sandflat into the lagoon should have increased recruitment to the latter habitat.

Transplants of coarse sediments from the sandflat to the lagoon failed to increase the recruitment of 3 of the 4 species (Rhinoclavis fasciata, $R$. vertagus and Cerithium zonatum) in the lagoon. For $R$. aspera, recruitment was significantly increased in the southern channel at 1 of the 2 locations, but not at the other. It would seem unlikely that the lack of a suitable substratum in the lagoon is the main causal factor for reduced recruitment of cerithiids to lagoonal habitats, but it clearly does play a role in limiting the distribution of at least 1 species at One Tree Reef.

The lesser recruitment of Rhinoclavis spp. into sediments within the lagoon may also be a function of a reduced number of larvae arriving over these sediments (e.g. Hannan 1981, Levin 1984, 1986). Water flow on the southern side of One Tree Reef is away from the carbonate reef crest and towards the lagoon at all stages of the tide (Davies \& West 1981). Larvae entrained in the water entering the reef from the southern side, therefore, first pass over the sandflat before reaching the finer sediments of the lagoon. If the majority of these larvae settle on the sandflat, fewer larvae will be available to settle in the lagoon and recruitment will be lower in that habitat. Gaines et al. (1985) proposed that settlement of barnacle cyprids at sites low on an intertidal shore caused depletion of the 'larval population' and led to reduced settlement higher on the shore. There were simply fewer larvae left to settle, by the time the water carrying the larvae reached the sites higher on the shore (see also Jackson 1986. Shapiro 1987). Alternatively, conditions in the water column over the lagoonal sediments may have prevented larvae from settling there (Underwood 1979, Connell 1985).

We indirectly and partially tested these alternative models with our experimental transplant of sediment between habitats. The presence of alternative substrata in the lagoon led to increased recruitment of one of the species of cerithiid gastropods, Rhinoclavis aspera, indicating that the larval pool was not totally depleted after the passage of the water across the sandflat. There were still abundant larvae of $R$. aspera left in the water over the lagoonal sediments.

Similarly, this discounts the possibility that recruitment of Rhinoclavis aspera was less in the lagoon due to unfavourable conditions preventing settlement
(Underwood 1979, Connell 1985). Replicate tubs of each treatment were randomly arranged within a site and repeated at 2 sites per location and would have been exposed to the same average set of conditions. The larvae were able to settle in greater numbers into the coarse sediment from the sandflat at 1 of the 2 locations. Why this pattern was not repeated at the second locations could not be determined.

These results also indicate that passive deposition of larvae (Butman 1987) is unlikely to be a critical factor in determining the distribution of recruits of Rhinoclavis spp. in sediments at One Tree Reef. The passive deposition model predicts that planktonic larvae initially settle at sites dictated by their size and relative fall velocities (Hannan 1984, Butman 1987). The larvae of these species of Rhinoclavis are probably of similar size as reported for other members of the Family Cerithiidae (Houbrick 1973). If all the larvae of Rhinoclavis spp. had 'fallen' onto the sandflat before reaching the lagoon then densities of recruits of $R$. aspera could not have increased (by a factor of 5) at 1 of the 2 locations in the lagoon when alternative substrata were provided.

The lack of a significant effect of transplanting sediment into the lagoon for the other 3 species did not allow us to clearly distinguish between the 3 models proposed to explain the patterns of recruitment in the lagoon and on the sandflat. We stress also that the results of this experiment cannot totally discount any of these models. Generally, numbers of recruits were smaller in the lagoon than on the sandflat and this could be indicative of depletion of larvae and/or an inability to settle. Further work should involve simultaneous estimates of the abundance of the larvae in the water as it passes across the sandflat and into the lagoon (e.g. see Hannan 1981, Levin 1984, 1986).

Composition of the habitat had a significant effect on the recruitment of all 4 species of cerithiids at the 2 locations on the sandflat and, in all cases, recruitment was greater in the sediments naturally occurring on the sandflat. This may have resulted from active habitat selection of a particular substratum (Meadows \& Campbell 1972, Gray 1974. Scheltema 1974) and/or post-settlement processes (Luckenbach 1984, Peterson 1986). Differential emigration from the treatments is unlikely to be a major factor; movements of juveniles of the cerithiids were very restricted (Skilleter 1990) and all tubs appeared to have been equally affected in relation to losses of sediment due to scouring from wind and tide-generated currents. The precise mechanisms to account for these effects require experiments in the laboratory because of the difficulties associated with observing larval settlement of infauna in the field (Butman 1987). 
Recruitment was significantly different between the coarse and very coarse sediments even though both were collected from the sandflat. Rhinoclavis aspera, $R$. vertagus and Cerithium zonatum each recruited in greater numbers into sediment from the centre of the sandflat, but $R$. fasciata recruited in greater numbers into sediment from near the reef crest. Williams (1980) also found significant variation in the recruitment of clams to 2 different sediments which had similar grain size and sorting. Evidently, small-scale differences in composition, within a single habitat, can affect recruitment and may help explain the large variability in recruitment among different locations on the sandflat (Skilleter 1992). These results support the contention that changes in the sediment inside predator exclusion cages on the sandflat at One Tree Reef may have led to reduced recruitment of $R$. aspera in the cages compared with outside (Jones et al. 1988). They suggested that the sediment was altered by greater deposition and/or retention of fine particles inside cages compared with open control areas. Artifacts such as these can have a marked effect on experimental results if the gastropods respond to differences in habitat composition. Such artifacts should be taken into account when interpreting results (see also Peterson 1979, Dayton \& Oliver 1980, Hulberg \& Oliver 1980)

The large variability in the density of recruits among locations which are only a few hundred metres apart may be due to small-scale heterogeneous distributions of larvae in the water column. Substantial variability in recruitment was most noticeable for Cerithium zonatum which was virtually restricted to a single location on the sandflat (see also Skilleter 1992). Similarly, a small trochid snail, Vamitrochis tragema (Melville \& Standen, 1986), which was rare on the sandflat, occurred in densities greater than $28000 \mathrm{~m}^{-2}$ at one location in the northern channel, but at only densities of about $3000 \mathrm{~m}^{-2}$ at a location $50 \mathrm{~m}$ away (Skilleter 1990). Doherty (1983) found that recruitment of a coral reef fish varied by a factor of 12 among reefs separated only by $15 \mathrm{~m}$ and suggested that at least some of these reefs had been colonised by small patches of larvae. This 'larval patch hypothesis' suggests that larvae may be aggregated by behaviour and local hydrodynamics accounting for small-scale variations in recruitment frequently observed over tens to hundreds of metres (Doherty 1987, Doherty \& Williams 1988). This hypothesis has also been used to explain small-scale temporal variations in recruitment, as patches of larvae move through an area (Victor 1984).

The importance of processes occurring at, or immediately after, settlement appears paramount for Rhinoclavis spp. at One Tree Reef. Although the greatest densities of recruits are found in the sediments on the sandflat, animals that 'manage' to recruit successfully into the finer lagoonal sediments have significantly faster rates of growth there (Skilleter \& Underwood unpubl.). Experimental manipulations of density and have also shown that this is not simply a function of there being smaller densities in the lagoon. What does this pattern of recruitment represent in terms of the life history stategies for these gastropods?

Strathmann (1985) indicated that feeding larvae may exploit several cues throughout their wide range of dispersal and may thus respond to unfavourable stimuli in some parts of their total distribution (Strathmann \& Branscomb 1979, Strathmann et al. 1981). One Tree Reef is towards the southern-most limit of the distribution of Rhinoclavis aspera, R. fasciata and R. vertagus (Houbrick 1978) and larvae may develop their 'preferences' from areas further north where demographic patterns may be different. Kay \& Switzer (1974) indicated that $R$. aspera in Fanning Lagoon, central Pacific Ocean, (near the centre of the range of distribution for these species) were most abundant in sediments with a mean particle size of about 0.90 to $1.30 \phi$ and occurred infrequently in finer or substantially coarser sediments. This range of values corresponds extremely closely to that found on the sandflat at One Tree Reef, but there are no data on patterns of recruitment to allow comparisons with the results obtained at One Tree Reef. The apparently maladaptive pattern of recruitment of Rhinoclavis spp. at One Tree Reef may not be representative of the demography of these species in general but this conclusion must await further research on this extremely common and abundant group of tropical coral reef gastropods.

One of the fundamental advances in marine ecology in the last decade has been the recognition that processes affecting the supply of invertebrate larvae to benthic habitats play an important role in regulating populations of animals in these habitats (Underwood \& Denley 1984, Connell 1985, Gaines et al. 1985, Roughgarden et al. 1986, Underwood \& Fairweather 1989). This acknowledgement of the importance of such processes has, for the most part, arisen from work in the rocky intertidal region. The present study demonstrates the great difficulty in attempting to unravel patterns and conflicting processes in a field experiment examining recruitment of mobile organisms in soft sediments. The problem arises in large part due to the great difficulty in identifying recent recruits in soft-sediment systems (Butman 1987). Yet, investigations of the causes of spatial and temporal variation in the number of recruits in different soft sediment habitats are needed before thinking on the topic is dominated by paradigms generated by studies in rocky intertidal habitats. Future experiments in soft sediments may prove more conclusive given some of the insights presented here 
Acknowledgements. This study was supported by a Commonwealth Postgraduate Research Award and grants (to G.A.S.) from the Australian Museum Postgraduate Assistance Scheme, Australian Coral Reef Society, Linnean Society of New South Wales and the Institute of Marine Ecology, University of Sydney. We wish to thank J. Delporte and D. Cable for assistance in the field and W. G. Ambrose, E. A. Irlandi, C. H. Peterson and K. L. Skilleter for comments on an early draft of this manuscript. This paper is a contribution from the University of Sydney, One Tree Island Field Station.

\section{LITERATURE CITED}

Butman, C. A. (1987). Larval settlement of soft-sediment invertebrates: the spatial scales of pattern explained by active habitat selection and the emerging role of hydrodynamic processes. Oceanogr. mar. Biol. A. Rev. 25: $113-165$

Commito, J. A., Boncavage, E. M. (1989). Suspension-feeders and coexisting infauna: an enhancement counter example. J. exp. mar. Biol. Ecol. 125: 33-42

Connell, J. H. (1985). The consequences of variation in initial settlement vs. post-settlement mortality in rocky intertidal communities. J. exp. mar. Biol. Ecol. 93; 11-45

Crowe, W. A., Josefson, A. B., Svane, I. (1987). Influence of adult density on recruitment into soft sediments: a short term in situ experiment. Mar Ecol. Prog. Ser. 4: 61-69

Davies, P. J., West, B. G. (1981). Suspended-sediment transport and water movement at One Tree Reef, southern Great Barrier Reef. BMR J. Aust. Geol. Geophys. 6: $187-195$

Dayton, P. K., Oliver, J. S. (1980). An evaluation of experimental analyses of population and community patterns in benthic marine environments. In: Tenore, K. R., Coull, B. C. (eds.) Marine benthic dynamics. Univ. of South Carolina Press, Columbia, p. 93-120

Doherty, P. J. (1983). Tropical territorial damselfishes: is density limited by aggression or recruitment? Ecology 64: $176-190$

Doherty, P. J. (1987). The replenishment of populations of coral reef fishes, recruitment surveys, and the problems of variability manifest on multiple scales. Bull. mar. Sci. 41 : $411-422$

Doherty, P. J., Williams, D. McB. (1988). The replenishment of coral reef fish populations. Oceanogr. mar. Biol. A. Rev. 26: $487-551$

Eckman, J. E. (1979). Small-scale patterns and processes in a soft-substratum intertidal community. J. mar. Res. 37: $437-457$

Eckman, J. E. (1983). Hydrodynamic processes affecting benthic recruitment. Limnol. Oceanogr. 28: 241-257

Eckman, J. E., Nowell, A. R. M., Jumars, P. A. (1981) Sediment destabilization by animal tubes. J. mar. Res. 39 $361-374$

Folk, R. L. (1980). Petrology of sedimentary rocks. Hemphill Publishing Company, Austin

Gaines, S. D., Brown, S., Roughgarden, J. (1985). Spatial variation in larval concentrations as a cause of spatial variation in settlement of the barnacle, Balanus glandula Oecologia 67: 267-272

Gallagher, E. D., Jumars, P. A., Trueblood, D. D. (1983) Facilitation of soft-bottom benthic succession by tube builders. Ecology 64: 1200-1216

Gray, J. S. (1974). Animal-sediment relationships. Oceanogr mar. Biol. A. Rev. 17: 223-261
Hannan, C. A. (1981). Polychaete larval settlement: correspondence of patterns in suspended jar collectors and in the adjacent natural habitat in Monterey Bay, California. Limnol. Oceanogr. 26: 159-171

Hannan, C. A. (1984). Planktonic larvae may act like passive particles in turbulent near-bottom flows. Limnol Oceanogr. 29: 1108-1116

Hartnoll, R. G. (1983). Substratum. In: Earll, R., Erwin, D. G. (eds.) Sublittoral ecology: the ecology of the shallow sublittoral benthos. Clarendon Press, Oxford, p. 97-124

Hines, A. H., Posey, M. H., Haddon, P. J. (1989). Effects of adult suspension-feeding bivalves on recruitment of estuarine infauna. Veliger 32: 109-119

Houbrick, J. R. (1973). Studies on the reproductive biology of the genus Cerithium (Gastropoda: Prosobranchia) in the Western Atlantic. Bull. mar. Sci. 23: 875-904

Houbrick, J. R. (1978). The family Cerithiidae in the IndoPacific. Part 1: The genera Rhinoclavis, Pseudovertagus and Clavocerithium. Monogr. mar. Mollusca 1: 1-130

Hulberg, L. W., Oliver, J. S. (1980). Caging manipulations in marine soft-bottom communities: importance of animal interactions or sedimentary habitat modifications. Can. J Fish. Aquat. Sci. 37: 1130-1139

Hunt, J. H., Ambrose, W. G., Peterson, C. H. (1987). Effects of the gastropod, Ilyanassa obsoleta (Say), and the bivalve, Mercenaria mercenaria (L.), on larval settlement and juvenile recruitment of infauna. J. exp. mar. Biol. Ecol. 108: $229-240$

Jackson, G. A. (1986). Interaction of physical and biological processes in the settlement of planktonic larvae. Bull. mar. Sci. 39: 202-212

Jones, G. P., Sale, P. F., Ferrell, D. J. (1988). Do large carnivorous fishes affect the ecology of macrofauna in shallow lagoonal sediments? A pilot experiment. Proc. 6th Int Coral Reef Symp. 2: 77-82

Jones, G. P. Ferrell, D. J., Sale, P. F. (1990). Spatial pattern in the abundance and structure of mollusc populations in the soft sediments of a coral reef lagoon. Mar. Ecol. Prog. Ser 62: $109-120$

Kay, E. A., Switzer, M. F. (1974). Molluscan distribution patterns in Fanning Island lagoon and a comparison of the molluscs of the lagoon and the seaward reefs. Pacif. Sci 28: 275-295

Keough, M. J., Downes, B. J. (1982). Recruitment of marine invertebrates: the role of active larval choices and early mortality. Oecologia 54: 348-352

Levin, L. A. (1984). Life history and dispersal patterns in a dense infaunal polychaete assemblage: community structure and response to disturbance. Ecology 65: 1185-1200

Levin, L. A. (1986). The influence of tides on larval availability in shallow waters overlying a mudflat. Bull. mar. Sci. 39: $224-233$

Luckenbach, M. W. (1984). Settlement and early post-settlement survival in the recruitment of Mulinia lateralis (Bivalvia). Mar. Ecol. Prog. Ser 17: 245-250

McGuinness, K. A., Underwood, A. J. (1986). Habitat structure and the nature of communities on intertidal boulders. J. exp. Mar. Biol. Ecol. 104: 97-123

Meadows, P. S., Campbell, J I. (1972). Habitat selection by aquatic invertebrates. Adv. mar. Biol. 10: 271-382

Peterson, C. H. (1979). Predation, competitive exclusion, and diversity on the soft-sediment benthic communities of estuaries and lagoons. In: Livingston, R. J. (ed.) Ecological processes in coastal and marine systems. Plenum Press, New York, p. 233-264

Peterson, C. H. (1986). Enhancement of Mercenaria mercenaria densities in seagrass beds: is pattern fixed during 
settlement season or altered by subsequent differential survival? Limnol. Oceanogr. 31. 200-205

Roughgarden, J., Gaines, S. D., Pacala, S. W. (1986). Supply side ecology. In: Gee, J. H. R., Gilles, P. S. (eds.) Organisation of communities: past and present. Blackwell Scientific Publications, Oxford, p. 491-518

Scheltema, R. S. (1974). Biological interactions determining larval settlement of marine invertebrates. Thalassia jugol. 10: $263-296$

Shapiro, D. Y (1987). Inferring larval recruitment strategies from the distributional ecology of settled individuals of a coral reef fish. Bull. mar. Sci. 41: 289-295

Skilleter, G. A. (1990). Population dynamics of three species of cerithiid gastropods in sediments at One Tree Reef. Ph.D. thesis, Univ. of Sydney

Skilleter, G. A. (1991). Distribution, abundance and sizestructure of cerithiid gastropods in sediments at One Tree Reef, southern Great Barrier Reef. J. exp. mar. Biol. Ecol. 151: $185-207$

Skilleter, G. A. (1992). Recruitment of cerithiid gastropods (Rhinoclavis spp.) in sediments at One Tree Reef, Great Barrier Reef. J. exp. mar. Biol. Ecol. 156: 1-21

Strathmann, R. (1985). Feeding and non-feeding larval development and life history evolution in marine invertebrates. A. Rev. Ecol. Syst. 16: 339-362

Strathmann, R. R., Branscomb, E. S. (1979). Adequacy of cues to favourable sites used by settling larvae of two intertidal barnacles. In: Stancyk, S. E. (ed.) Reproductive ecology of marine invertebrates. Univ. of South Carolina Press, Columbia, p. 77-89

Strathmann, R. R., Branscomb, E. S., Vedder, K. (1981). Fatal

This article was submitted to the editor errors in set as a cost of dispersal and the influence of intertidal flora on set of barnacles. Oecologia 48: 13-18

Underwood, A. J. (1979). The ecology of intertidal gastropods. Adv. mar. Biol. 16: 111-210

Underwood, A. J. (1981). Techniques of analysis of variance in experimental marine biology and ecology. Oceanogr. mar. Biol. A. Rev. 19: 513-605

Underwood, A. J., Denley, E. J. (1984). Paradigms, explorations and generalisations in models for the structure of intertidal communities on rocky shores. In: Strong, D. J., Simberloff, D. S., Thistle, A. B. (eds.) Ecological communities: conceptual issues and the evidence. Princeton Univ. Press, Princeton, p. 151-180

Underwood, A. J., Fairweather, P. G. (1989). Supply side ecology and benthic marine assemblages. TREE $4: 16-20$

Victor, B. C. (1984). Coral reef fish larvae: patch size estimation and mixing in the plankton. Limnol. Oceanogr 29: $1116-1119$

Williams, J. G. $(1980)$. The influence of adults on the settlement of the clam, Tapes japonica. J. mar Res. 38: $729-741$

Winer, B. J. (1971). Statistical principles in experimental design. McGraw-Hill Kogakusha, Tokyo

Woodin, S. A. (1978). Refuges, disturbance, and community structure: a marine soft-bottom example. Ecology 59: $274-284$

Woodin, S. A. (1981). Disturbance and community structure in a shallow water sand flat. Ecology 62: 1052-1066

Zajac, R. N., Whitlatch, R. W. (1982). Responses of estuarine infauna to disturbance. I. Spatial and temporal variation of initial recolonisation. Mar. Ecol. Prog. Ser. 10: 1-14

Manuscript first received: August 11, 1992

Revised version accepted: December 21, 1992 